\title{
Perancangan Aplikasi Mobile Learning Perkecambahan pada Mata Pelajaran Biologi Berkarakter Bangsa
}

\author{
Engineering of Mobile Learning Application for Germination Subject in National \\ Characterized Biology Course \\ Detri Setiyowati ${ }^{1}$, Much Aziz Muslim ${ }^{2}$ \\ 1,2 Jurusan Ilmu Komputer, FMIPA, Universitas Negeri Semarang \\ Jalan Taman Siswa, Sekaran, GunungPati, Semarang, 50229 \\ e-mail: ${ }^{1}$ detri09@students.unnes.ac.id, ${ }^{2}$ a212muslim@yahoo.com
}

\begin{abstract}
Abstrak
Perkembangan teknologi yang semakin maju memungkinkan untuk pemanfaatan yang optimal. Salah satunya pada bidang pendidikan. Dengan berkembangnya TIK, pembelajaran yang ada dimaksimalkan dan beralih dari metode konvensional yaitu guru ceramah menjadi pembelajaran yang interaktif. Mobile learning adalah pembelajaran dengan memanfaatkan teknologi informasi yang dapat diakses secara fleksibel (dimana saja dan kapan saja). Pendidikan Indonesia yang saat ini mengarah ke pendidikan karakter membuat penulis menyediakan adanya fasilitas penilaian karakter berdasarkan penggunaan aplikasi. Penilaian karakter ini disesuaikan dengan keterkaitan karakter bangsa dalam mata pelajaran dan nilai bobot karakter dalam sebuah media. Penelitian ini menggunakan metode MDLC (Multimedia development life cycle) dalam pengembangan aplikasi dan metode alfa beta dalam pengujian kelayakan aplikasi menggunakan skala likert. Pengujian yang dilakukan menghasilkan skala 3.625 yang menyatakan aplikasi ini layak untuk digunakan.
\end{abstract}

Kata Kunci: aplikasi, mobile learning, biologi, $M D L C$

\begin{abstract}
The development of increasingly advanced technology allows for optimal utilization. One of them in the field of education. With the development of ICT, existing learning is maximized and shifted from conventional methods of teacher lectures into interactive learning. Mobile learning is learning by utilizing information technology that can be accessed flexibly (anywhere and anytime). Education Indonesia is currently leading to character education makes the author provides a character assessment facility based on the use of the application. Assessment of this character is tailored to the relevance of national character in the subjects and the value of character weights in a medium. This research uses MDLC (Multimedia development life cycle) method in application development and alpha beta method in testing the feasibility of application using Likert scale. The test resulted in a scale of 3.625 which states the application is feasible to use.
\end{abstract}

Keywords: application, mobile learning, biology, $M D L C$

\section{PENDAHULUAN}

Metode pembelajaran pendidikan Indonesia masih sering dijumpai dengan metode konvensional. Dengan perkembangan teknologi saat ini yang semakin pesat, metode konvensional yang digunakan dalam kelas dinilai kurang efektif dan efisien. Siswa akan mudah merasa jenuh dengan metode pembelajaran guru ceramah dan siswa hanya mendengarkan atau membaca buku dengan teks dan gambar statis. Siswa perlu waktu lebih untuk memahami materi karena metode konvensional kurang menarik. Kurikulum, proses pembelajaran, metode pengajaran, evaluasi, buku ajar, mutu guru, saran dan prasarana pendidikan dapat mempengaruhi kualitas dari pendidikan tiap sekolah [1]. Mobile learning merupakan model dari pembelajaran yang memanfaatkan teknologi informasi dan komunikasi. Konsep model pembelajaran ini membawa manfaat ketersediaan materi yang dapat di akses dimana dan kapan saja dengan visualisasi materi yang menarik dan interaktif. Hal ini mengacu kepada penggunaan 
perangkat teknologi informasi genggam dan bergerak, seperti smartphone yang dapat digunakan dalam pengajaran dan pembelajaran [2].

Menurut Ghozi (2014) bahwa mobile learning menjadi salah satu alternatif untuk permasalahan pemerataan akses infomasi pendidikan, kualitas konten pembelajaran yang berupa materi pembelajaran baik bentuk teks ataupun gambar disertai dengan contoh-contoh soal serta peningkatan kualitas pendidik agar lebih baik dalam membuat atau menyampaikan materi pembelajaran dan mengelola kegiatan belajar mengajar sehingga terwujud kegiatan belajar mengajar yang menarik dan interaktif serta tercapai tujuan pembelajaran yang diharapkan[3]. Dalam hal ini akan diimplementasikan dalam mata pelajaran biologi, yang mana biologi adalah salah satu mata pelajaran IPA yang tergolong ilmu kognitif. Ilmu kognitif adalah studi interdisipliner dari pikiran dan sifat intelijen. Hal ini mencakup kemampuan intelektual dan kemampuan berpikir seseorang. Selain itu, pendidikan di Indonesia telah mulai mengarah pada pengembangan pendidikan karakter dan tidak lagi hanya terpaku pada hasil belajar kognitif.

Perkembangan teknologi informasi yang sangat pesat telah membuat banyak perubahan bagi kehidupan dan menuntut manusia untuk memanfaatkan teknologi dalam berbagai bidang [4]. Salah satu bidang yang menjadi tombak mencerdasakan bangsa adalah bidang pendidikan. Di bidang pendidikan pemanfaatan teknologi di lakukan dalam proses pembelajaran yang bertujuan agar menciptakan minat siswa untuk belajar dan memudahkan siswa dalam mempelajari materi. Selain itu media pembelajaran berbasis multimedia juga dapat meningkatkan efisiensi hasil belajar dan meningkatkan efektifitas belajar [5].

Penggunaan media dalam pembelajaran memiliki beberapa manfaat yang positif, seperti keseragaman dalam penyampaian materi, proses pembelajaran menjadi lebih jelas dan menarik, proses pembelajaran menjadi lebih interaktif, efisiensi waktu dan tenaga, meningkatkan kualitas hasil belajar siswa, media memungkinkan proses belajar dapat dilakukan di mana saja dan kapan saja, media dapat menumbuhkan sikap positif siswa terhadap materi dan proses belajar, mengubah peran guru kearah yang lebih positif dan produktif. Kuantitas smartphone user dengan intensitas penggunaan yang terbilang tinggi dapat dioptimalkan dengan implementasi mobile learning dalam bidang pendidikan untuk mewujudkan pembelajaran yang menarik dan interaktif dalam memudahkan pemahaman materi biologi serta pengembangan karakter bangsa bagi penggunanya.

Pada penelitian sebelumnya yang berjudul Perancangan Mobile Learning Berbasis Android Pada Mata Kuliah Sistem Operasi Di Stmik Indonesia Padang [6] aplikasi ini bertujuan untuk mengakomodasi dan memfasilitasi mahasiswa pada semester ganjil dalam mempelajari sistem operasi dan menggunakan metode SDLC (System Development Life Cycle) dalam perancangannya. Kemudian pada penelitian Aplikasi Mobile Informasi Pariwisata Kota Semarang Berbasis Android [7] mengimplementasikan model pengembangan sistem waterfall dan berfungsi untuk menampilkan informasi terkait Kota Semarang dan membantu pengguna mengetahui letak lokasi yang akan dikunjungi dengan memanfaatkan GPS. Penelitian sebelumnya berjudul Media Pembelajaran Animasi Penyerbukan pada Tumbuhan Menggunakan Macromedia Flash 8 [8] bertujuan untuk memungkinkan siswa tertarik dan mudah untuk belajar serta memahami mata pelajaran biologi khususnya tentang siklus penyerbukan. Media pembelajaran ini dilengkapi gambaran visual tentang proses daur hidup tumbuhan, bagian tanaman dan proses penyerbukan. Metode pembuatan media ini menggunakan metode waterfall.

Melihat realita yang ada, muncul ide gagasan untuk membuat Aplikasi Mobile Learning Perkecambahan pada Mata Pelajaran Biologi Berkarakter Bangsa yang bertujuan untuk mewujudkan pembelajaran yang menarik dan interaktif dalam memudahkan pemahaman materi biologi serta pengembangan karakter bangsa bagi penggunanya.

\section{METODE PENELITIAN}

Metode yang digunakan dalam perancangan aplikasi mobile learning perkecambahan ini menggunakan MDLC (Multimedia development life cycle) yaitu metode dengan 6 tahap. Tahapan dalam metode ini berupa, penentuan Concept (Konsep), Design (Desain / Rancangan), Material Collecting (Pengumpulan Materi), Assembly (Penyusunan dan Pembuatan), Testing (Uji Coba) dan Distribution (Menyebar Luaskan) [9].

\subsection{Concept}


Tahap ini merumuskan dasar dari perancangan apikasi berupa tujuan, sasaran dan analisis kebutuhannya. Tujuan dibuatnya aplikasi ini membantu siswa dalam memahami materi dan mengembangkan karakter bangsa dengan mengoptimalkan penggunaan smartphone. Sasaran perancangan aplikasi ini untuk siswa SMA kelas 12. Pada perancangan aplikasi mobile learning perkecambahan kebutuhan ini terdiri dari dua analisis yakni analisis software: Adobe Flash Professional CS6, Corel Draw X7 dan analisis hardware: Prosesor Pentium IV, RAM 512 MB atau lebih tinggi, Free Space HD 10GB, Resolusi monitor 1024 x 768 px.

\subsection{Design}

Tahap design menjabarkan secara rinci mengenai arsitektur program, gaya dan tampilan. Tahap design aplikasi mobile perkecambahan berkarakter bangsa ini memerlukan GBIM (Garis Besar Isi Media), JM (Jabaran Materi) dan Storyboard. GBIM merujuk pada silabus dan RPP yang dimiliki oleh guru sehingga tercipta kesesuaian dengan materi. JM berisi uraian materi pokok secara terperinci menyesuaikan standar kompetensi dan kompetensi dasar yang disusun. Struktur aplikasi Perkecambahan ini dapat dilihat pada Gambar 1.

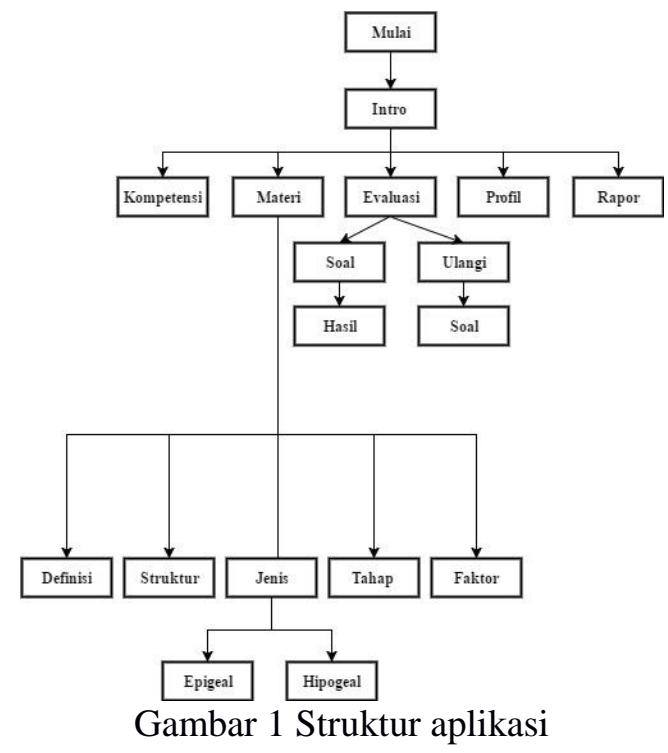

Tahap desain memerlukan storyboard, storyboard digunakan untuk menggambarkan alur perancangan desain tampilan aplikasi mobile learning perkecambahan berkarakter bangsa dan menggambarkan deskripsi tiap scene. Storyboard aplikasi mobile learning perkecambahan dijelaskan pada Tabel 1.

Tabel 1 Storyboard perancangan aplikasi

\begin{tabular}{|c|c|c|c|l|}
\hline Scene & \multicolumn{2}{|c|}{ Board } & Durasi & \multicolumn{1}{c|}{ Naskah } \\
\hline 1 & Loading... & 10 & $\begin{array}{l}\text { Tampilan awal aplikasi berupa } \\
\text { detik }\end{array}$ & $\begin{array}{l}\text { scene loading sebelum pengguna } \\
\text { diarahkan ke menu utama. Selain } \\
\text { loading terdapat pula animasi } \\
\text { pembuka berupa logo jateng dan } \\
\text { animasi "Perkecambahan". }\end{array}$ \\
& & & \\
\hline
\end{tabular}




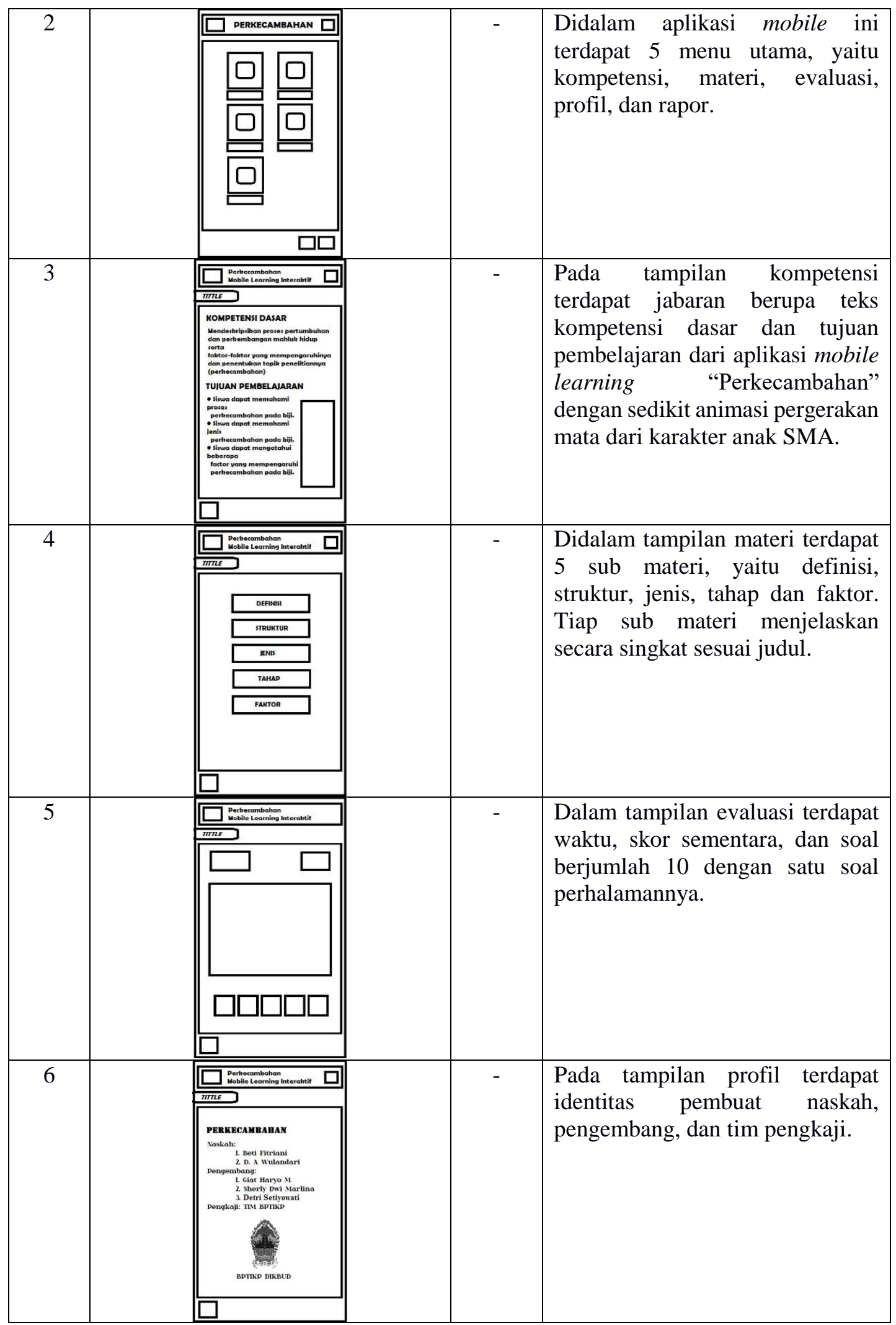




\begin{tabular}{|c|c|c|c|}
\hline 7 & 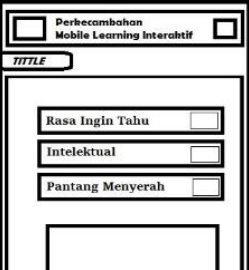 & - & $\begin{array}{l}\text { Setiap nilai yang didapatkan dari } \\
\text { klik navigasi/hidden button yang } \\
\text { memuat nilai karakter akan } \\
\text { ditampilkan pada rapor meliputi: } \\
\text { rasa ingin tahu, intelektual dan } \\
\text { pantang menyerah. }\end{array}$ \\
\hline & $\square$ & & \\
\hline
\end{tabular}

\subsection{Material collecting}

Tahap ini merupakan proses untuk pengumpulan segala sesuatu yang dibutuhkan dalam perencanaan dalam merancang aplikasi mobile learning. Mengenai materi yang akan disampaikan dan gambar yang akan dimasukkan dalam penyajian perencanaan aplikasi mobile learning.

\subsection{Assembly}

Mengimplementasikan perencanaan aplikasi mobile learning. Materi-materi serta file-file multimedia yang sudah didapat kemudian dirangkai dan disusun sesuai desain. Pada proses ini sangat dibutuhkan kemampuan dari ahli agar mendapatkan hasil yang baik. Pembuatan Tampilan menggunakan Adobe Flash Professional CS6 karena memiliki fasilitas yang dapat digunakan dalam pembuatan background, gambar, dan animasi sekaligus sehingga mempermudah dalam proses pembuatan Tampilan.

\subsection{Testing}

Evaluasi atau pengujian aplikasi ini menggunakan metode alfa dan beta. Metode ini menyajikan kuesioner terkait aplikasi yang dibuat dan disebarkan ke sampel sasaran pengguna aplikasi. Pengujian ini menghasilkan nilai bobot setiap tanggapan yang ditentukan poin perjawaban (Sangat Setuju, Setuju, Netral, Tidak Setuju atau Sangat Tidak Setuju) kemudian poin tiap pertanyaan akan dijumlahkan. Jumlah poin tersebut akan digunakan untuk menentukan angka kategori yang dihitung sehingga nilai tersebut dapat menunjukkan kelayakan dari aplikasi mobile learning perkecambahan ini. Pengujian alfa dilakukan dengan ahli media yaitu salah satu dosen di Jurusan Kurikulum dan Teknologi Pendidikan Universitas Negeri Semarang dengan mengacu pada kualitas aplikasi. Hasil uji kelayakan yang didapat yaitu 3.625, sehingga aplikasi dikatakan layak untuk digunakan. Sedangkan untuk pengujian beta, kuesioner dibagikan kepada 25 sampel siswa MAN 2 Kebumen. Hasil pengujian menunjukkan 32\% menyatakan aplikasi layak, 52\% menyatakan cukup layak dan 16\% menyatakan kurang layak.

\subsection{Distribution}

Dalam tahapan ini, aplikasi mobile learning perkecambahan yang telah diuji dan dinyatakan layak dan sesuai dengan tujuan perancangan, akan didistribusikan/dipublikasikan ke Jateng Pintar sebagai bahan referensi untuk belajar.

\section{HASIL DAN PEMBAHASAN}

Media pembelajaran ini berbasis android atau bisa disebut mobile learning tentang mata pelajaran biologi SMA Perkecambahan yang dibuat dengan Adobe Flash Profesional CS6 dan Bahasa pemrograman Actionscript 3. Pada penelitian sebelumnya perancangan mobile learning kurang fleksibel dan terkesan monoton. Konten yang disajikan lebih mengutamakan materi tertulis, sehingga tampilan aplikasi kaku dan kurang menarik. Aplikasi mobile learning perkecambahan ini menambahkan beberapa animasi dan juga fitur rapor dimana pengguna dapat melihat hasil nilai karater bangsa yang diperoleh. Gambar 2 merupakan tampilan awal aplikasi berupa scene loading sebelum pengguna diarahkan ke menu utama. Selain loading terdapat pula animasi pembuka berupa logo Jateng dan animasi tulisan "Perkecambahan". 

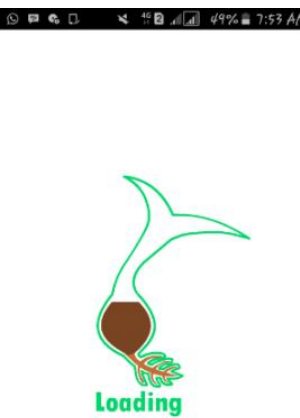

\section{Gambar 2 Tampilan scene loading}

Gambar 3 menyajikan menu yang ada dalam aplikasi mobile learning perkecambahan dengan 5 menu utama yaitu kompetensi, materi, evaluasi, profil dan rapor. Menu kompetensi berisi kompetensi dasar dan tujuan pembelajan berdasarkan topik pembahasan dalam aplikasi yaitu tentang perkecambahan. Menu materi berisi definisi, struktur, jenis, faktor dan tahapan dalam perkecambahan. Menu evaluasi berisi latihan soal tentang perkecambahan. Menu profil memuat nama pembuat dari aplikasi. Terakhir menu rapor berisi bobot karakter berdasarkan nilai karakter dalam sebuah media dengan mengacu pada keterkaitan mata pelajaran terhadap karakter bangsa.

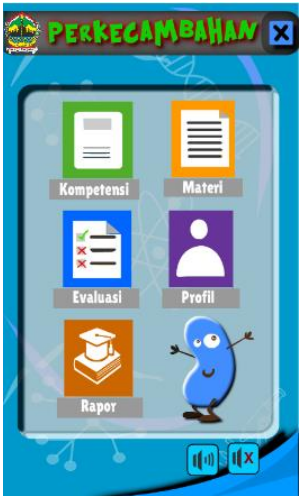

Gambar 3 Tampilan menu utama aplikasi

Gambar 4 merupakan scene materi dengan 5 sub menu. Button definisi sendiri memuat pengertian dari perkecambahan. Button struktur berisi dari struktur biji, dengan disajikan gambar dan button. Ketika button ditekan maka akan muncul pop up tentang fungsi dari masing-masing struktur biji. Button jenis menyajikan animasi dari jenis perkecambahan, sehingga siswa dapat melihat secara langsung perbedaannya. Button tahap memuat beberapa tahapan yang dilewati dalam proses perkecambahan. Button faktor menjelaskan 5 faktor yang mempengaruhi perkecambahan.

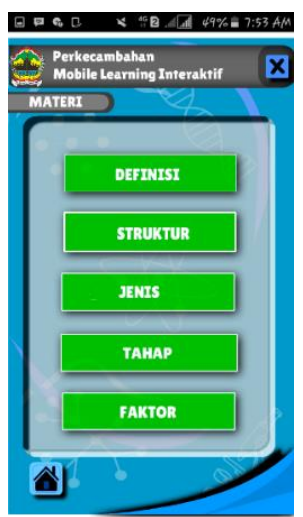




\section{Gambar 4 Tampilan scene materi}

Gambar 5 merupakan scene evaluasi yang menyediakan latihan soal berdasarkan materi yang tersedia. Pada scene ini tedapat 10 soal dengan batas waktu pengerjaan 2 menit. Siswa dapat melihat skor yang didapat dan siswa dapat juga mengulanginya.

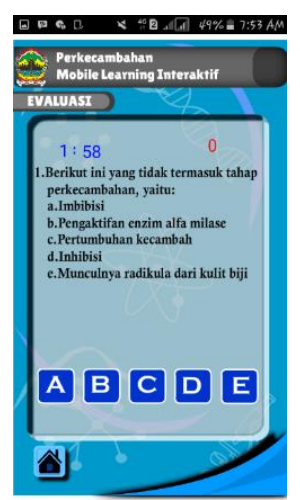

Gambar 5 Tampilan scene evaluasi

Gambar 6 yaitu scene rapor berisi nilai karakter tiap pemakaian berupa rasa ingin tahu, intelektual, dan pantang menyerah. Nilai karakter ini disesuaikan dengan karakter yang tersembunyi didalam aplikasi. Nilai dapat berubah berdasarkan berapa kali pengguna menekan tombol tersembunyi yang mempengaruhi nilai karakter pada scene rapor ini. Karakter yang tersedia disesuaikan dengan bentuk nilai karakter dalam sebuah media.

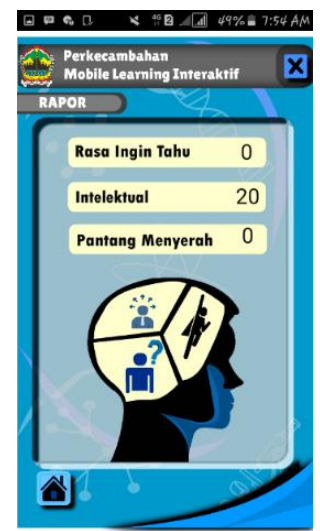

Gambar 6 Tampilan scene rapor

Evaluasi aplikasi mobile perkecambahan menggunakan pengujian alfa dan beta. Pengujian alfa dilakukan oleh pihak ahli media untuk mengecek kelayakan aplikasi dengan mengisi kuesioner yang disediakan. Penentuan penilaian yang digunakan yaitu skala Likert. Skala penilaian Likert dapat dilihat pada Tabel 2.

Tabel 2 Skala penilaian likert

\begin{tabular}{|c|c|c|c|}
\hline No. & Jawaban & Keterangan & Nilai \\
\hline $\mathbf{1 .}$ & SS & Sangat Setuju & 5 \\
\hline $\mathbf{2 .}$ & S & Setuju & 4 \\
\hline $\mathbf{3 .}$ & N & Netral/Tidak Berpendapat & 3 \\
\hline $\mathbf{4 .}$ & TS & Tidak Setuju & 2 \\
\hline $\mathbf{5 .}$ & STS & Sangat Tidak Setuju & 1 \\
\hline
\end{tabular}


Nilai bobot setiap tanggapan ahli media akan ditentukan poin perjawaban (SS, S, N, TS atau STS) kemudian poin tiap pertanyaan akan dijumlahkan. Jumlah poin tersebut akan digunakan untuk menentukan angka kategori yang dihitung dengan rumusan persamaan 1, yaitu angka kategori (K) didapat dari jumlah poin likert (f) dibagi jumlah ahli media $(\mathrm{N})$.

$$
K=\frac{f}{N}
$$

Hasil penilaian ahli media, akan dimasukkan dalam garis kontinum kelayakan dengan mengacu skor yang diperoleh. Model garis kontinun kelayakan yang digunakan disajikan seperti pada Gambar 7 .

\begin{tabular}{|c|c|c|c|c|c|}
\hline & $\begin{array}{l}\text { Tidak } \\
\text { Layak }\end{array}$ & $\begin{array}{c}\text { Kurang } \\
\text { Layak }\end{array}$ & $\begin{array}{l}\text { Cukup } \\
\text { Layak }\end{array}$ & Layak & $\begin{array}{l}\text { Sangat } \\
\text { Layak }\end{array}$ \\
\hline 0,5 & 1 & 2 & 3 & 4 & 5 \\
\hline
\end{tabular}

Pengujian aplikasi dilakukan dengan memberikan kuesioner kepada ahli media yang mengacu pada kualitas dari aplikasi. Hasil pengujian ahli media dapat dilihat pada Tabel 3

Tabel 3 Hasil pengujian kelayakan aplikasi ahli media

\begin{tabular}{|c|c|c|c|c|c|c|c|c|}
\hline No. & Pernyataan & SS & $\mathbf{S}$ & $\mathbf{N}$ & TS & STS & $\begin{array}{c}\text { Angka } \\
\text { Kategori }\end{array}$ & Kategori \\
\hline 1. & $\begin{array}{l}\text { Icon/tombol yang memudahkan } \\
\text { pengguna dalam menggunakan } \\
\text { aplikasi mobile learning } \\
\text { perkecambahan }\end{array}$ & & $\mathrm{v}$ & & & & 4 & Layak \\
\hline 2. & $\begin{array}{l}\text { Kemudahan dalam pencarian } \\
\text { konten (kurikulum, materi, } \\
\text { evaluasi, info) pada aplikasi } \\
\text { mobile learning perkecambahan }\end{array}$ & & & & $\mathrm{v}$ & & 2 & $\begin{array}{l}\text { Kurang } \\
\text { Layak }\end{array}$ \\
\hline 3. & $\begin{array}{l}\text { Gambar dan animasi yang } \\
\text { disajikan telah sesuai dengan } \\
\text { materi }\end{array}$ & & $\mathrm{v}$ & & & & 4 & Layak \\
\hline 4. & $\begin{array}{l}\text { Kesesuaian penggunaan warna } \\
\text { teks dan jenis huruf pada aplikasi } \\
\text { mobile learning perkecambahan }\end{array}$ & & & $\mathrm{V}$ & & & 3 & $\begin{array}{l}\text { Cukup } \\
\text { Layak }\end{array}$ \\
\hline 5. & $\begin{array}{l}\text { Kesesuaian bentuk evaluasi } \\
\text { dengan konsep materi } \\
\text { perkecambahan yang disajikan } \\
\end{array}$ & & $\overline{\mathrm{v}}$ & & & & 4 & Layak \\
\hline 6. & $\begin{array}{l}\text { Kemudahan dan kesederhanaan } \\
\text { dalam pengoperasian pada } \\
\text { aplikasi mobile learning } \\
\text { perkecambahan }\end{array}$ & $\mathrm{v}$ & & & & & 5 & $\begin{array}{l}\text { Sangat } \\
\text { Layak }\end{array}$ \\
\hline 7. & $\begin{array}{l}\text { Materi dalam aplikasi mobile } \\
\text { learning perkecambahan } \\
\text { tersampaikan dengan padat dan } \\
\text { jelas }\end{array}$ & & & $\mathrm{v}$ & & & 3 & $\begin{array}{l}\text { Cukup } \\
\text { Layak }\end{array}$ \\
\hline 8. & Kalimat mudah dipahami & & $\mathrm{v}$ & & & & 4 & Layak \\
\hline \multicolumn{7}{|c|}{ Jumlah } & 29 & \\
\hline \multicolumn{7}{|c|}{ Rata-rata } & 3.625 & Layak \\
\hline
\end{tabular}

Berdasarkan perhitungan pada Tabel 3 dengan pengujian pada ahli media, aplikasi mobile learning perkecambahan berkarakter bangsa dinilai Layak dengan rata-rata hasil 3.625. Untuk pengujian beta dilakukan kepada beberapa calon pengguna/user yaitu siswa Sekolah Menengah Atas dengan melibatkan 25 siswa MAN 2 Kebumen. Hasil pengujian menunjukkan 52\% pengguna menilai 
aplikasi Cukup Layak digunakan, 32\% menilai Layak dan 16\% menilai aplikasi Kurang Layak. Perhitungan yang dilakukan disajikan dalam bentuk diagram seperti Gambar 8.

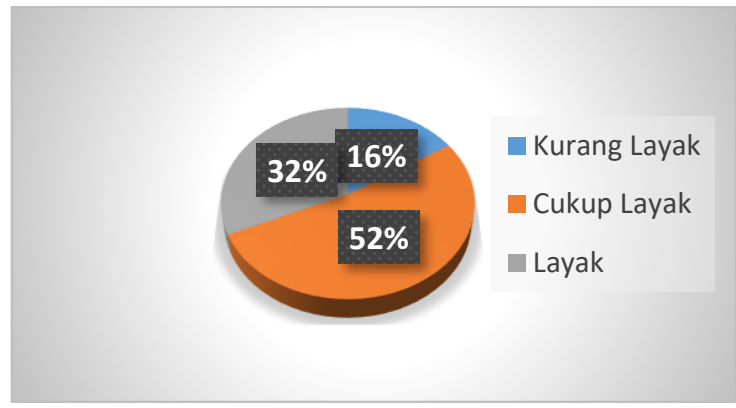

Gambar 8 Hasil pengujian pengguna

\section{KESIMPULAN}

Perancangan aplikasi mobile learning perkecambahan pada mata pelajaran biologi berkarakter bangsa dengan flash yang perlu diperhatikan adalah kesesuaian materi dengan kurikulum, desain interface, dan perancangan media yang interaktif. Dalam pembuatan juga sangat diperlukan perhatian terhadap kode-kode program agar aplikasi berjalan dengan baik. Aplikasi mobile learning Perkecambahan memberikan kemudahan bagi guru dalam menyampaikan materi tentang proses perkecambahan pada tumbuhan, dan siswa dapat mempelajari materi kapan saja dan dimana saja sesuai keinginan. Dengan adanya aplikasi ini siswa lebih tertarik dalam proses pembelajaran dan dapat memahami materi lebih cepat dibandingkan dengan pembelajaran dengan metode konvensional. Berdasarkan pengujian kelayakan yang telah dilakukan dengan ahli media, aplikasi mobile learning perkecambahan ini dinilai layak untuk digunakan dan didistribusikan dengan hasil pengujian sebesar 3.625 berdasarkan skala likert. Sedangkan untuk pengujian yang dilakukan dengan sample user didapat $32 \%$ pengguna mengatakan aplikasi mobile learning perkecambahan layak digunakan, 52\% cukup layak dan $16 \%$ kurang layak.

\section{SARAN}

Penulis menyarankan pengembangan mobile learning ditingkatkan pada materi animasi tiga dimensi sehingga materi dapat tersampaikan lebih menarik dan interaktif. Selain itu, diharapkan peneliti lain mengembangkan media pembelajaran sejenis dengan materi yang berbeda dan dapat diterapkan langsung dalam proses pembelajaran yang sebenarnya sehingga siswa tidak merasa jenuh dengan pembelajaran konvensional.

\section{UCAPAN TERIMA KASIH}

Ucapan terima kasih ditujukan kepada Fakultas Matematika dan Ilmu Pengetahuan Alam, Universitas Negeri Semarang atas dukungan dan terlaksananya penelitian ini.

\section{DAFTAR PUSTAKA}

[1] Fitria, Aida, N., \& Nurhayati. (2014). Pengembangan Media Pembelajaran Perkuliahan Dasar Sistem Telekomunikasi Mahasiswa S1 Teknik Elektro. Jurnal Pendidikan Elektro, Vol. 3(3): 579-585.

[2] Furqon, C., \& Sunandang, A. (2016). Aplikasi Mobile Learning (M-Learning) Untuk Mata Kuliah Pengantar Teknologi Informasi Berbasis Java 2 Micro Edition (J2me). Jurnal Wawasan Ilmiah.

[3] Ghozi, S. (2014). Pengembangan Materi Mobile learning dalam Pembelajaran Matematika Kelas X SMA Perguruan Cikini Kertas Nusantara Berau. Indonesian Digital Journal of Mathematics and Education.

[4] Muslim, M., \& Astri, R. N. (2014). Implementasi Cloud Computing Menggunakan Metode Pengembangan Sistem Agile. Scientific Journal of Informatics, 29-38. 
[5] Syafrizal, A., Ernawati, \& Dwiandiyanta, B. (2015). Penerapan Model Technology Acceptance Model (TAM) untuk Pemahaman Media Pembelajaran Berbasis Multimedia Interaktif. Scientific Journal of Informatics, 9-14.

[6] Rahmelina, L. (2017). Perancangan Mobile Learning berbasis Android pada Mata Kuliah Sistem Operasi di STMIK INDONESIA PADANG. Jurnal Informatika.

[7] Wibowo, T. I., \& Setiyanto, N. A. (2016). Aplikasi Mobile Informasi Pariwisata Kota Semarang Berbasis Android. techno.com, 124-133.

[8] Wibowo, S., \& Nilawati, F. E. (2015). Media Pembelajaran Animasi Penyerbukan pada Tumbuhan Menggunakan Macromedia Flash 8. Techno.com, 151-158.

[9] Sutopo, H. (2009). Pengembangan Model Pembelajaran Pembuatan Aplikasi Multimedia Khususnya Puzzle Game pada Mata Kuliah Multimedia. Jakarta: Universitas Negeri Jakarta. 